\title{
Other Becketts: Series Preface General Editor: S. E. Gontarski, Florida State University
}

In I997 Apple computers launched an advertising campaign (in print and on television) that entreated us to 'Think Different', and Samuel Beckett was one of Apple's icons. Avoiding Apple's solecism, we might modify the appeal to say that Other Becketts is a call to think differently as well, in this case about Beckett's work, to question, that is, even the questions we ask about it. Other Becketts, then, is a series of monographs focused on alternative, unexplored or under-explored approaches to the work of Samuel Beckett, not a call for novelty per se, but a call to examine afresh those of Beckett's interests that were more arcane than mainstream, interests that might be deemed quirky or strange, and those of his works less thoroughly explored critically and theoretically, the late prose and drama, say, or even the poetry or criticism. Volumes might cover (but are not restricted to) any of the following: unusual illnesses or neurological disorders (the 'duck foot, goose foot' of First Love, akathisia or the invented duck's disease or panpygoptosis of Miss Dew in Murphy, proprioception, or its disturbance, in Not I, perhaps, or other unusual neurological lapses among Beckett's creatures, from Watt to the Listener of That Time); mathematical peculiarities (irrational numbers, factorials, Fibonacci numbers or sequences, or non-Euclidian approaches to geometry); linguistic failures (from Nominalism to Mauthner, say); citations of or allusions to contrarian aesthetic philosophers working in a more or less irrationalist tradition (Nietzsche, Bergson or Deleuze, among others), or in general 'the simple games that time plays with space'. Alternative approaches would be of interest as well, with foci on objects, animals, cognitive or memory issues, and the like. 


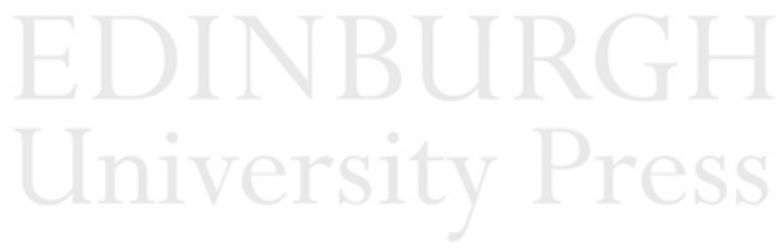

Not for distribution or resale. For personal use only. 